\section{Relación entre la vulneración del derecho de bonificación y su tratamiento en el proceso contencioso administrativo por preparación de clases de los docentes de la Unidad de Gestión Educativa Local - San Martín, 2018
Relationship between the violation of the bonus right and its treatment in the contentious-administrative process for preparing classes for teachers of the Local Educational Management Unit - San Martín, 2018
Ruiz Paredes, Gelver ${ }^{1}$ y Moreno Aguilar, Jhin Demetrio 9605]
${ }^{1}$ Universidad Nacional de San Martín, Tarapoto, Perú gelverruizpegmail.com

\begin{abstract}
Resumen. Esta investigación tiene como objetivo general determinar cuál es la relación entre la vulneración del derecho de bonificación y su tratamiento en el proceso contencioso administrativo por preparación de clases de los docentes de la UGEL - San Martín, 2018. La investigación es mixta, con diseño no experimental de índole descriptivo correlacional de corte transversal. La muestra estudiada es de 132 procesos contenciosos administrativos, que tienen como pretensiones el reconocimiento del $30 \%$ de sus remuneraciones por preparación de clases y evaluación, de los resultados obtenidos se aceptó la hipótesis alterna que establece que existe una relación significativa entre las variables estudiadas; por lo que se concluyó que se vulneró sistemáticamente el derecho solicitado en el año 2018 en un 99.25\%, puesto que, la Sala Civil Descentralizada de Tarapoto revocaron las sentencias de primera instancia y consecuentemente la declararon improcedentes las demandas contenciosas administrativas.
\end{abstract}

\section{Palabras Clave: bonificación, contencioso, derecho, instancia, proceso}

Abstract. The general objective of this research is to determine what is the relationship between the violation of the bonus right and its treatment in the contentious-administrative process for class preparation of the UGEL teachers - San Martín, 2018. The research is mixed, with non-experimental design of a descriptive correlational cross-sectional nature. The sample studied consists of 132 administrative contentious processes, which claim the recognition of $30 \%$ of their remuneration for class preparation and evaluation, from the results obtained, the alternative hypothesis was accepted that establishes that there is a relationship significant among the variables studied; Therefore, it was concluded that the right requested in 2018 was systematically violated by $99.25 \%$, since the Decentralized Civil Chamber of Tarapoto revoked the first instance judgments and consequently declared the contentious claims inadmissible. administrative. 


\section{$1 \quad$ Introducción}

Los profesores del Perú cumplen un rol fundamental, sentando las bases del desarrollo integral de nuestros educandos, por su acertada labor educativa el estado reconoció en su oportunidad específicamente el 20 de mayo de 1990 a través de la Ley Nº 24029 - Ley del Profesorado, que fue posteriormente modificada por la Ley $\mathrm{N}^{\circ} 25212$, la misma que reconoce en su artículo 48 que: "El profesor tiene derecho a percibir una bonificación especial mensual por preparación de clases y evaluación equivalente al $30 \%$ de su remuneración total.", asimismo, el artículo 210 del Decreto Supremo N 19-90-ED publicada en el Diario Oficial El Peruano el 29 de julio de 1990, dispuso en su primer párrafo que: "El profesor tiene derecho a percibir una bonificación especial mensual por preparación de clases y evaluación equivalente al 30\% de su remuneración total. Ante la falta de reconocimiento de la administración pública, los docentes deben emprender sendos procesos administrativos y luego recurrir al poder judicial en la vía del proceso contencioso administrativo, entendido por Salas (2013), quien manifiesta, que según el Artículo 24 de la Ley 27584 que regula el Proceso Contencioso Administrativo, este corresponde a acto sumarísimo, por lo aparentemente es un proceso célere.

En ese sentido la bonificación especial por preparación de clases es un beneficio y derecho fundamental de carácter especial, que se les otorgó a los profesores en actividad de todo el Perú, activos y jubilados, no obstante, existe un conflicto de interpretación normativa en el sector educación y los administrados, sobre la base del cálculo de la bonificación especial por preparación de clases, interpretando los primeros que debería hacerse sobre la base de la remuneración de la remuneración permanente contrario sensu los administrados aducen que dicho derecho debe realizarse en base a la remuneración total o íntegra. Conflicto jurídico que ha conlleva a que se active la justicia ordinaria en mérito de las demandas contenciosas administrativas, para que el Poder Judicial con la finalidad de que ejerza el control jurídico de las actuaciones de la administración pública, conforme lo establece el artículo 148 de la constitución política de 1993. Del mismo modo en la investigación realizada por Piedra (2015), en su tesis: $E l$ procedimiento contencioso administrativo. Para optar el título de abogado, Universidad Nacional de Loja, Ecuador. El autor llegó a la conclusión que La Constitución de la República dispone en el art. 173 que: "Los actos administrativos de cualquier autoridad del Estado podrán ser impugnados, tanto en la vía administrativa como ante los correspondientes órganos de la Función Judicial." Es decir que no es necesario agotar la vía administrativa para poder impugnar vía judicial. Normas jurídicas del mismo nivel que regulan acciones similares a fin de proteger a los administrados.

El problema de esta investigación radica en que, la Unidad de Gestión Educativa Local, Dirección Regional de Educación y el Gobierno Regional de San Martín, durante más de 20 años de la

Citar como: Moreno Aguilar, J. D., \& Ruiz Paredes, G. (2021). Relación entre la vulneración del derecho de bonificación y su tratamiento en el proceso contencioso administrativo por preparación de clases de los docentes de la Unidad de Gestión Educativa Local - San Martín, 2018. Revista Científica Ratio lure, 1(1), 32-44. https://doi.org/10.51252/rcri.v1i1.126 
vigencia de la Ley $\mathrm{N}^{\circ} 24029$, modificada por Ley $\mathrm{N}^{\circ} 25212$, han venido reconociendo el derecho de bonificación especial por preparación de clases de los profesores a su cargo en base a su remuneración total permanente, cuando la ley menciona que es en base a la remuneración total. La presente investigación se desarrolló con una muestra de 132 resoluciones judiciales, las mismas que fueron obtenidos del Sistema Integrado de Justicia de manera on-line, aplicación que se encuentra disponible al público para consultas de procesos extrapenales de la Sala Civil Descentralizada de la provincia de San Martín, a través de la búsqueda de expedientes judicial superior de la página oficial del Poder Judicial, todas ellas tramitadas conforme lo dispuesto en el D.S. 013-2008-JUS, norma especial que se regula para su tramitación en el Perú, sin embargo este trámite no recibe en la hermana república del ecuador, por lo que Vicuña (2015), en su tesis: El Nuevo Procedimiento Contencioso Administrativo. Para la obtención de título de Máster en Derecho Administrativo, Universidad San Francisco de Quito, Ecuador. El autor llegó a la conclusión que en la regulación del procedimiento contencioso administrativo no se han considerado las particularidades y especificidades de esta materia, se ha normado de manera muy general a un proceso muy particular; por lo que para el caso de investigación fue más específica la evaluación de las variables de estudio, por encontrarse específicamente regulado cada actuación dentro del proceso judicial.

Tenemos como objetivo general: determinar cuál es la relación entre la vulneración del derecho de bonificación y su tratamiento en el proceso contencioso administrativo por preparación de clases de los docentes de la Unidad de Gestión Educativa Local - San Martín, 2018, y dos específicos siendo el primero: describir la vulneración el derecho de bonificación especial por preparación de clases de los docentes de la Unidad de Gestión Educativa Local - San Martín, 2018 y el segundo describir los aspectos del tratamiento en el proceso contencioso administrativo por preparación de clases de los docentes de la Unidad de Gestión Educativa Local - San Martín, 2018.

\section{Materiales y Métodos}

La investigación fue de tipo mixta: Se considera mixta, porque la parte cualitativa corresponde al análisis documentario de las resoluciones judiciales emitidas por la Sala Civil Descentralizada de Tarapoto y la parte cuantitativa corresponde a los datos obtenidos mediante la ficha de observación de cada una de las resoluciones. Los análisis cuantitativos se interpretan a la luz de las predicciones iniciales (hipótesis) y de estudios previos (teoría). Hemos considerado como población 200 sentencias de vista, luego aplicamos la fórmula para poblaciones finitas, obteniendo como muestra 132 resoluciones pertenecientes a procesos contenciosos administrativos sobre derecho de bonificación especial por preparación de clases, tramitados en

Citar como: Moreno Aguilar, J. D., \& Ruiz Paredes, G. (2021). Relación entre la vulneración del derecho de bonificación y su tratamiento en el proceso contencioso administrativo por preparación de clases de los docentes de la Unidad de Gestión Educativa Local - San Martín, 2018. Revista Científica Ratio lure, 1(1), 32-44. https://doi.org/10.51252/rcri.v1i1.126 
la Sala Civil Descentralizada de la Provincia de San Martín de la Corte Superior de Justicia de San Martín, resueltos en el año dos mil dieciocho.

En la hipótesis planteada por el autor, se estableció como hipótesis que existe una relación positiva y significativa entre el derecho de bonificación y su tratamiento en el proceso contencioso administrativo por preparación de clases de los docentes de la Unidad de Gestión Educativa Local - San Martín, 2018. En la definición operacional de las variables de estudio tenemos dos: variable 1: Vulneración del derecho de bonificación especial por preparación de clases; como dimensión consideramos: la interpretación extensiva de la norma, lo que nos permitirá conocer cuál es la relación entre la vulneración del derecho de bonificación y su tratamiento en el PCA por preparación de clases de los docentes de la Unidad de Gestión Educativa Local - San Martín, 2018. Y la variable 2: Tratamiento en el proceso contencioso administrativo; Esta variable ha sido operacionalizada a través de una dimensión relacionada a las decisiones judiciales, las cuales confirman o revocan la sentencias de primera instancia. En el presente trabajo de investigación se utilizó para la primera variable de estudio la técnica de análisis documentario y su ficha de registro como instrumento, para la segunda variable se utilizó como técnica la observación y su instrumento la ficha de observación.

Tabla 1

Operacionalización de variables

\begin{tabular}{llll}
\multicolumn{1}{c}{ Variables } & \multicolumn{1}{c}{ Dimensiones } & \multicolumn{1}{c}{ Indicadores } & Escala de Medición \\
\hline $\begin{array}{l}\text { Variable 1. Vulneración del derecho } \\
\text { de bonificación especial por }\end{array}$ & $\begin{array}{l}\text { Interpretación extensiva de } \\
\text { preparación de clases }\end{array}$ & No vulnerados & SI / NO \\
$\begin{array}{l}\text { Variable 2. Tratamiento en el proceso } \\
\text { contencioso administrativo }\end{array}$ & Decisiones judiciales & $\begin{array}{c}\text { Vulnerados } \\
\text { Confirmadas } \\
\text { Revocadas }\end{array}$ & SI / NO \\
\hline
\end{tabular}

Fuente: Elaboración propia

\section{Resultados y discusiones}

\section{Resultados}

En esta investigación, el primer objetivo específico fue describir cómo se vulnera el derecho de bonificación especial por preparación de clases de los profesores de la Unidad de Gestión Educativa Local - San Martín, 2018. En ese sentido, los resultados se tomaron teniendo como referencia la remuneración total o integra y la remuneración permanente, considerándose que las resoluciones donde se reconoció el derecho de bonificación especial por preparación de clases no se vulnero el derecho, es decir se confirmaron las decisiones de primera instancia y por el contrario en donde se declararon improcedentes las demandas se utilizó como criterio que el derecho ha sido vulnerado, describiendo cada uno de los fundamentos de las decisiones judiciales según de la aplicación la técnica del análisis documentario y el instrumento fue una ficha de registro. Dichos resultados se contemplan en la tabla tres.

Citar como: Moreno Aguilar, J. D., \& Ruiz Paredes, G. (2021). Relación entre la vulneración del derecho de bonificación y su tratamiento en el proceso contencioso administrativo por preparación de clases de los docentes de la Unidad de Gestión Educativa Local - San Martín, 2018. Revista Científica Ratio lure, 1(1), 32-44. https://doi.org/10.51252/rcri.v1i1.126 
Tabla 2

Vulneración del derecho de bonificación especial por preparación de clases de los docentes de la Unidad de Gestión Educativa Local - San Martín, 2018

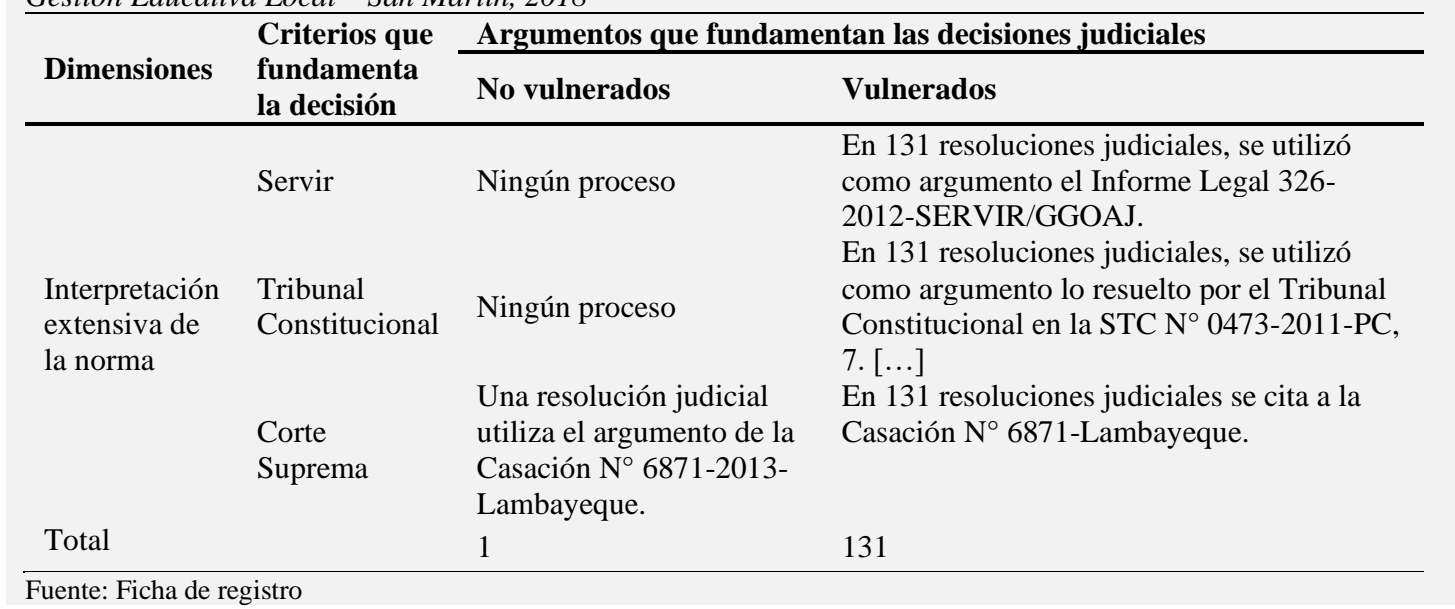

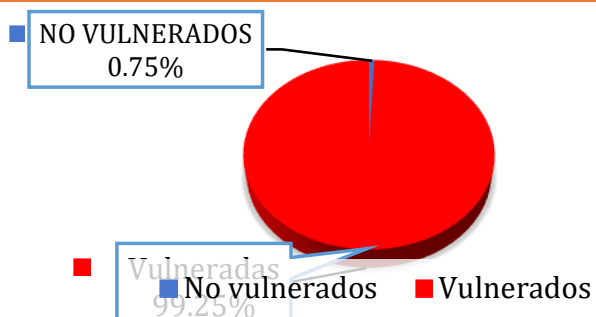

Figura 1: Resultado de las resoluciones sobre el derecho de bonificación especial por preparación de clases de los docentes de la Unidad de Gestión Educativa Local - San Martín, 2018

Interpretación: de la figura 1, se observa que 131 resoluciones judiciales emitidas por la Sala Civil Descentralizada de Tarapoto, de la Corte Superior de Justicia de San Martín, que fueron resueltas en el año dos mil dieciocho, lo cual representa el 99.25\% han sido declaradas improcedentes, en donde se evidencia que no se reconoció el derecho de bonificación especial por preparación de clases a los docentes de la Unidad de Gestión Educativa Local de la Provincia de San Martín. Por su parte, solo una resolución reconoció dicho derecho a uno de los maestros, lo cual representa el $0.75 \%$ de las resoluciones consideradas como muestra para esta investigación.

Del mismo modo, el segundo objetivo específico fue, describir cómo es el tratamiento en el proceso contencioso administrativo de los procesos iniciados por los profesores de la Unidad de Gestión Educativa Local - San Martín, 2018. Para ello, se consideró las decisiones judiciales, como referencia las que fueron confirmadas y revocadas, siendo las primeras las resoluciones que reconocieron la bonificación especial por preparación de clases de conformidad con el artículo 48 de la ley 24029 modificada por la ley 25212 y las segundas que fueron desestimadas declarándose improcedentes amparándose en el artículo 10 del Decreto Supremo 051-091-PCM ; se utilizó en

Citar como: Moreno Aguilar, J. D., \& Ruiz Paredes, G. (2021). Relación entre la vulneración del derecho de bonificación y su tratamiento en el proceso contencioso administrativo por preparación de clases de los docentes de la Unidad de Gestión Educativa Local - San Martín, 2018. Revista Científica Ratio lure, 1(1), 32-44. https://doi.org/10.51252/rcri.v1i1.126 
el recojo de información el instrumento denominado ficha de observación con su técnica de observación.

Tabla 3

Tratamiento en el proceso contencioso administrativo de los procesos iniciados por los profesores de la Unidad de Gestión Educativa Local - San Martín, 2018

\begin{tabular}{llcc}
\hline & \multicolumn{2}{c}{ Decisiones Judiciales } \\
\cline { 2 - 4 } Condición & $\mathbf{N}^{\circ}$ & $\%$ & 0.75 \\
\hline $\begin{array}{l}\text { Resoluciones } \\
\text { judiciales de la Sala }\end{array}$ & Confirmadas & 1 & 99.25 \\
$\begin{array}{l}\text { Civil Descentralizada } \\
\text { de Tarapoto, año 2018. }\end{array}$ & Revocadas & 131 & 100 \\
\hline Total & & 132 & \\
\hline Fuente: Ficha de observación & &
\end{tabular}

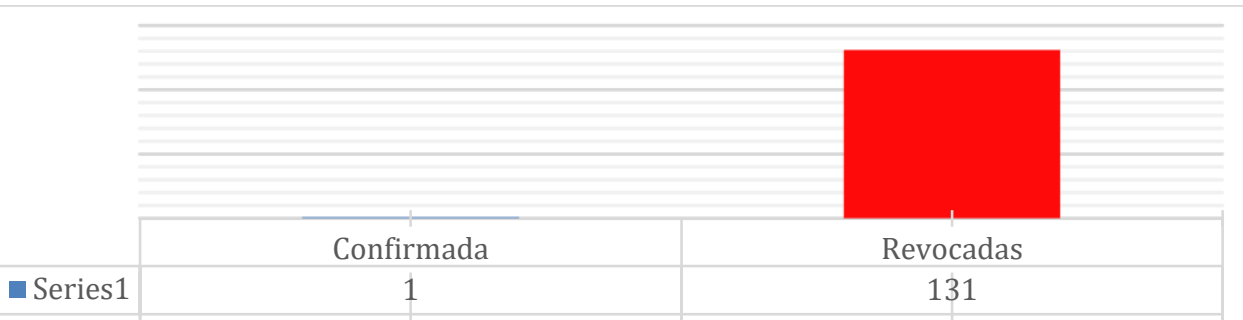

Figura 2: Tratamiento en el proceso contencioso administrativo de los procesos iniciados por los profesores de la Unidad de Gestión Educativa Local - San Martín, 2018

Interpretación: en el gráfico se puede observar que, 131 sentencias de vista, expedidas por la Sala Civil Descentralizada de Tarapoto de la Corte Superior de Justicia de San Martin, revoca la sentencia que declara fundada la demanda sobre pago de la bonificación especial por preparación de clases en primera instancia, significando ello el cambio de la decisión primigenia en la cual se declararon fundadas. Asimismo, puede apreciarse que solo una sentencia fue declarada fundada en primera instancia y confirmada por la Sala Civil Descentralizada de Tarapoto.

Finalmente, en la presente investigación el objetivo general fue: Determinar la relación entre la vulneración del derecho de bonificación y su tratamiento en el proceso contencioso administrativo por preparación de clases de los docentes de la UGEL - San Martín, 2018. Para la investigación planteamos la Ha: Existe una relación significativa entre la vulneración del derecho de bonificación y su tratamiento en el proceso contencioso administrativo por preparación de clases de los docentes de la Unidad de Gestión Educativa Local - San Martín, 2018.

Citar como: Moreno Aguilar, J. D., \& Ruiz Paredes, G. (2021). Relación entre la vulneración del derecho de bonificación y su tratamiento en el proceso contencioso administrativo por preparación de clases de los docentes de la Unidad de Gestión Educativa Local - San Martín, 2018. Revista Científica Ratio lure, 1(1), 32-44. https://doi.org/10.51252/rcri.v1i1.126 
Tabla 4

Tabla de contingencia

\begin{tabular}{llll}
\hline \multirow{2}{*}{ Variables } & \multicolumn{2}{l}{ V2: Proceso contencioso administrativo } \\
\cline { 3 - 4 } & Revocado / vulnerado & $\begin{array}{l}\text { Confirmado / no } \\
\text { vulnerado }\end{array}$ \\
\hline $\begin{array}{l}\text { V1: Vulneración del derecho } \\
\text { de bonificación especial por } \\
\text { preparación de clase }\end{array}$ & Vulnerados & 131 & 0 \\
Fuente: Sistematización de aplicación de los instrumentos & 0 & 1 \\
\hline
\end{tabular}

Tabla 5

Frecuencias esperadas

\begin{tabular}{llll}
\hline Indicadores & Revocado & Confirmado & Total \\
\hline Vulnerados & 130.0075 & 0.99 & 131 \\
No vulnerados & 0.99 & 0.0075 & 1 \\
Total & 131 & 1 & 132 \\
\hline
\end{tabular}

Fuente: Calculado a partir de los totales contemplados en la tabla 7

\begin{tabular}{llll}
\hline Frecuencias observadas $(\mathbf{O})$ & Frecuencias esperadas $(\mathbf{E})$ & O-E & $(\mathbf{O}-\mathbf{E})^{2} / \mathbf{E}$ \\
\hline 131 & 130.0075 & 0.9925 & 0.00758 \\
0 & 0.9900 & -0.9900 & 0.99000 \\
0 & 0.9900 & -0.9900 & 0.99000 \\
1 & 0.0075 & 0.9925 & 131.34083 \\
\hline Chi cuadrado calculado & & & 133.32841
\end{tabular}

La determinación del Chi Cuadrado calculado, se detalla en la siguiente tabla.

Determinación del Chi cuadrado teórico o de tabla

Para obtener el Chi Cuadrado de tabla, se realizó con los grados de libertad; el cual es: (número de filas -1$)^{*}($ número de columnas -1$)=(2-1) *(2-1)=1$. Así como el nivel de significancia: $\alpha=$ 0.05. Por tanto, si vamos a la tabla de Chi cuadrado para gl. $=1$ y $\alpha=0.05$; notamos que el Chi Cuadrado de tabla es igual a: 3.841. Realizando el contraste de hipótesis, cómo el Chi Cuadrado calculado es mayor que el Chi Cuadrado de tabla $(133,328>3,841)$, entonces se rechaza la hipótesis nula y se acepta la hipótesis alterna.

\section{Discusión}

Según el objetivo general de la investigación: Determinar la relación entre la vulneración del derecho de bonificación y su tratamiento en el proceso contencioso administrativo por preparación de clases de los docentes de la Unidad de Gestión Educativa Local - San Martín, 2018. A partir de los resultados encontrados, aceptamos la hipótesis alterna que establece que existe una relación significativa positiva entre las variables de estudio; teniendo como resultado en el contraste de hipótesis que el Chi Cuadrado es mayor que el Chi Cuadrado de la tabla

Citar como: Moreno Aguilar, J. D., \& Ruiz Paredes, G. (2021). Relación entre la vulneración del derecho de bonificación y su tratamiento en el proceso contencioso administrativo por preparación de clases de los docentes de la Unidad de Gestión Educativa Local - San Martín, 2018. Revista Científica Ratio lure, 1(1), 32-44. https://doi.org/10.51252/rcri.v1i1.126 
$(133,328>3,841)$. Estos resultados concuerdan con los obtenidos por Izquierdo (2019), quien considera que existe relación significativa entre los principios del procedimiento administrativo y la bonificación de preparación de clases y evaluación en la UGEL Moyobamba en el año 2019, en donde se obtuvo u Rho de Spearman de 0.67. resultado que se contradice con lo resuelto en el Juzgado de Trabajo Transitorio de Tarapoto, Sentencia Expediente No 992-2015-0-2208-JM-LA02, 2017, donde se señaló en el sexto considerando que "El artículo 48 de la Ley 24029 - Ley del Profesorado, y su modificatoria Ley 25212, prescribe que: "El profesor tiene derecho a percibir una bonificación especial mensual por preparación de clases y evaluación equivalente al 30\% de su remuneración total".

Referente a la vulneración del derecho de bonificación por preparación de clases, obtenidos lo resultados de las sentencias de vista, emitidos por la Sala Civil Descentralizada de Tarapoto, se registró que falló en un 99.25\% de sus sentencias de vista del año 2018, referentes a la pretensión principal de declaración de nulidad de resoluciones administrativa expresas y fictas, así como a las pretensiones objetivas originarias accesorias, porcentaje de decisiones judiciales que fueron declaradas improcedentes, significado este porcentaje que se desestimó las pretensiones, por tanto se vulnero el derecho de bonificación por preparación de clases; toda vez que los criterios que asumió la Sala Civil fue conforme al informe legal 326-2012-SERVIR/GGOAJ, que estableció como procedente administrativo de observancia obligatoria que la bonificación especial no se encuentra incluido dentro de la remuneración total o integra. Similar criterio es asumido por el Tribunal Constitucional en la Sentencia $N^{\circ}$ 047-2011-PC, en su fundamento siete donde interpreta que debe aplicarse el artículo 10 del decreto supremo 051-91-PCM, señalando que precisa que lo dispuesto en el artículo 48 de la ley del profesorado $\mathrm{N}^{\circ} 24019$, modificada por la ley $\mathrm{N}^{\circ} 25212$, se aplica sobre la remuneración total permanente. Los argumentos considerados por Servir y el Tribunal Constitucional para declarar improcedentes las demandas de los docentes, se contradice con los resultados encontrados por Vela (2015), en donde concluye que la falta de presupuesto es lo que ocasiona el atraso en el pago de bonificaciones por preparación de clases y evaluación a los docentes; en donde da entender que dicha bonificación es un derecho que le asiste a todo docente, precisando que la falta de pagó es un factor en el pagó, significando ello que no se les restringe la bonificación sino señalando que existen meramente trámites administrativos, por otro lado también la decisión del colegiado se condice con lo resuelto por las Primera Sala de Derecho Constitucional y Social Transitoria en la Casación 8368-2016-San Martín (2018), que precisa que la base de cálculo de la bonificación especial por preparación de clases se debe efectuar de acuerdo al artículo 48 de la ley de profesorado, modificado por el artículo 1 de la ley 25212 y no la remuneración total permanente que señala el artículo $10^{\circ}$ del Decreto Supremo $N^{\circ}$ 051-91-PC.

Citar como: Moreno Aguilar, J. D., \& Ruiz Paredes, G. (2021). Relación entre la vulneración del derecho de bonificación y su tratamiento en el proceso contencioso administrativo por preparación de clases de los docentes de la Unidad de Gestión Educativa Local - San Martín, 2018. Revista Científica Ratio lure, 1(1), 32-44. https://doi.org/10.51252/rcri.v1i1.126 
Por el contrario, una de las decisiones judiciales que representa el $0.75 \%$ de la muestra estudiada, confirmo la resolución de primera instancia, reconociendo el derecho de bonificación especial por preparación de clases y evaluación, decisión que coincide con lo resuelto en la Casación $\mathrm{N}^{\circ}$ 68712013-Lambayeque, que estableció como precedente judicial vinculante que la bonificación especial por preparación de clases y evaluación es sobre la base de la remuneración total o integra, por su parte el blog de consultas legales, PUCP (2012) precisa que a todo profesor de aula, le es aplicable el artículo $48^{\circ}$ de la Ley 24029 , concordante con el artículo $210^{\circ}$ del Decreto Supremo $\mathrm{N}^{\mathrm{o}}$ 19-90-ED, Reglamento de la Ley del Profesorado. Del mismo modo se señala en las Casaciones № 16286-2016-San Martín y Casación 7122-2016- San Martín, que precisan que la forma de calculo es en base a la remuneración total o integra. Al respecto Príncipe (2015), considera que las demandas sobre recálcalo y pago de bonificación por preparación de clases y evaluación iniciado por los docentes cesantes del régimen pensionario 20530, no hay discusión o cuestionamiento de la vía procesal, en efecto la vía del proceso contencioso administrativo ordinario es lo adecuado para viabilizar todas las acciones sobre pago de bonificación por preparación de clases y evaluación, resultando en este extremo un tema no discutible. La Sala Civil Descentralizada de Tarapoto pese a tener conocimiento de las decisiones de la Corte Suprema, sobre el criterio asumido en sendas casaciones, interpreta indebidamente amparándose en el informe de SERVIR y el Tribunal Constitucional, como se señala up supra el criterio que se asumió para confirmar la sentencia de vista, fue de acuerdo a la remuneración total integra; por su parte la Segunda Sala de Derecho Constitucional y Social Transitoria de la Corte Suprema de Justicia de la República (2015), en la Casación 6871-2013, señala como Precedente Judicial Vinculante $\mathrm{N}^{\circ}$ 02-2015-2da. SDCST, concluyendo que conforme al artículo 48 de la ley 24019, se calcula en base a la remuneración total, coincidiendo con el resultado obtenido en la única resolución en mención.

Con respecto al segundo objetivo específico de estudio, se realiza a través del resultado de resoluciones judiciales confirmadas y revocadas, fallos que se obtenido de los procesos contenciosos administrativos resueltos por la Sala Civil Descentralizada de Tarapoto de la Corte Superior de Justicia de San Martín, resoluciones que pertenecen a los procesos judiciales que tienen como petitorio la nulidad de las resoluciones administrativas expresas y fictas, que se dictaron en la Dirección Regional de San Martín y como pretensión acumulativa objetiva originaria accesoria el reconocimiento del derecho de bonificación especial por preparación de clases y evaluación. Se obtuvo 131 sentencias de vista declaradas improcedente, significando ello que se revoca la decisión de primera instancia del Juzgado Especializado en la cual fueron declaradas fundadas, por el contrario, solo se percibe que una sola decisión fue declarada fundada en primera instancia y confirmada por la segunda instancia. Resultado que se contradice con

Citar como: Moreno Aguilar, J. D., \& Ruiz Paredes, G. (2021). Relación entre la vulneración del derecho de bonificación y su tratamiento en el proceso contencioso administrativo por preparación de clases de los docentes de la Unidad de Gestión Educativa Local - San Martín, 2018. Revista Científica Ratio lure, 1(1), 32-44. https://doi.org/10.51252/rcri.v1i1.126 
Juárez (2016), cuando analiza la calidad de sentencias de primera y segunda instancia sobre contenciosa administrativa por nulidad de resolución administrativa expediente $\mathrm{N}^{\circ} 00594-2008$ 0-3101-JR-CI-02. Juárez que la calidad en relación con la sentencia de primera instancia se puede decir que es baja calidad y en cuanto a la sentencia de segunda instancia de muy alta calidad. Resultado contrapuesto a lo obtenido en la investigación por cuanto en segunda instancia se muestra lo contrario se revocaron las decisiones de primera instancia en un porcentaje de $99.25 \%$ del total de la muestra. Lo resuelto de marera mayoritaria por la sala civil descentralizada de Tarapoto de acuerdo a los resultados encontrados, coinciden con Sala M. (2018) donde concluye que la Unidad de Gestión Educativa Local $\mathrm{N}^{\circ} 04$ arbitrariamente realiza el cálculo de la bonificación especial por preparación de clases y evaluación aplicando el Decreto Supremo $\mathrm{N}^{\circ}$ 051-91- PCM, siendo que reiterada jurisprudencia ha establecido que el cálculo de la bonificación especial tiene que realizarse en función a la remuneración total, tal como lo establece la Ley del Profesorado $\mathrm{N}^{\circ} 24029$, modificada por Ley $\mathrm{N}^{\circ} 25212$. De los resultados obtenidos y la conclusión arribada por el tesista se advierte que en sede administrativa y vía judicial se vulnera evidentemente el derecho de bonificación especial de clases y evaluación. Resultados contrarios encontramos en Ramírez (2017), que señala que un aspecto que limita la acción de la justicia en los procesos contenciosos es la recargada carga laboral de los encargados de la defensa jurídica del Estado, motivando muchas veces que las sentencias sean desfavorables hacia la administración pública. Resultado que refuta con los resultados encontrados, por cuanto se obtuvo que la administración pública representado por el Ministerio de Educación, con lo resuelto por la Sala Civil Descentralizada de Tarapoto, estaría fallando a favor al declarar improcedentes las demandas contenciosas administrativas.

En opinión del autor el cálculo de la bonificación especial por preparación de clases y evaluación debe realizarse en base al artículo 48 de la ley 24029 , modificado por la ley $\mathrm{N}^{\circ} 25212$, en base a la remuneración permanente, criterio que se refuerza con lo resuelto en las casaciones números CAS-8368, CAS-12286, CAS-7122 del año 2016, las mismas que fueron expedidas producto de los recursos extraordinarios de casación que se impugnaron en la misma Sala Civil Descentralizada de Tarapoto, donde resolvieron que el cálculo se debe hacer en base al cálculo de la remuneración total permanente. En tal sentido debe entenderse la remuneración total permanente y los conceptos remunerativos adicionales otorgados por ley expresa, los mismos que se dan por el desempeño de cargos que implican exigencias y/o condiciones distintas al común. De lo expuesto, se colige que la remuneración total permanente, está incluida dentro del concepto de remuneración total, que es más amplio, siendo esta remuneración total a la que se refiere el artículo 48 de la Ley del Profesorado número 24029; así como también el inciso b) del artículo 208 y el 210 del Decreto Supremo N 019-90-ED, Reglamento de la Ley del Profesorado.

Citar como: Moreno Aguilar, J. D., \& Ruiz Paredes, G. (2021). Relación entre la vulneración del derecho de bonificación y su tratamiento en el proceso contencioso administrativo por preparación de clases de los docentes de la Unidad de Gestión Educativa Local - San Martín, 2018. Revista Científica Ratio lure, 1(1), 32-44. https://doi.org/10.51252/rcri.v1i1.126 


\section{Conclusiones}

Existe una relación significativa entre el derecho de bonificación y su tratamiento en el proceso contencioso administrativo por preparación de clases de los docentes de la Unidad de Gestión Educativa Local - San Martín, 2018, porque en el contraste de hipótesis se obtuvo que el Chi Cuadrado calculado es mayor que el Chi Cuadrado de la tabla $(133,328>3,841)$. Por tanto, se aceptó la hipótesis alterna de esta investigación.

Se vulneró sistemáticamente el derecho de bonificación y su tratamiento en el proceso contencioso administrativo por preparación de clases de los docentes de la Unidad de Gestión Educativa Local - San Martín, 2018; en un $99.25 \%$ de la muestra, puesto que, la Sala Civil Descentralizada de Tarapoto, apoyándose de los argumentos del Tribunal Servir y el Tribunal Constitucional, deniegan el derecho solicitado, señalando que no les corresponde percibir conforme lo estable el artículo 48 de la ley 24029, modificada por la ley 25212.

El tratamiento en el proceso contencioso administrativo de los procesos tramitados por los docentes de la Unidad de Gestión Educativa Local - San Martín, 2018, es ineficiente puesto que, se aprecia que en un $99.25 \%$ de decisiones judiciales de la Sala Civil Descentralizada de Tarapoto de la Corte Superior de Justicia de San Martin, revoca la sentencia que declara fundada la demanda en primera instancia, reformándola y declarando improcedente la demanda en todos sus extremos; lo que refleja una labor poco efectiva por parte de los operadores jurídicos en la defensa de los derechos de los docentes.

\section{Referencias bibliográficas}

Juzgado de Trabajo Transitorio de Tarapoto (2017). Sentencia Exp. N 992-2015-0- 2208-JMLA-02.

Juárez (2016). Calidad de sentencias de primera y segunda instancia sobre acción contenciosa administrativa por nulidad de resolución administrativa expediente $n^{\circ} 00594-2008-0-3101-J R-C I-$ 02. Distrito Judicial de Sullana Piura, 2016. Universidad Católica Los Ángeles Chimbote, PiuraPerú.

Piedra (2015). El procedimiento contencioso administrativo, Universidad Nacional de Loja, Ecuador.

Príncipe (2015). Vía del proceso contencioso administrativo y retribución por preparación de clases y evaluación para docentes cesantes del régimen pensionario 20530 en la Provincia de Barranca, años 2010-2014; Universidad Nacional José Faustino Sánchez Carrión.

Vela (2015). Incumplimiento de sentencias firmes sobre pago de bonificaciones en la UGEL Pachitea. Universidad de Huánuco-Perú.

Vicuña (2015). El Nuevo Procedimiento Contencioso Administrativo, Universidad San Francisco de Quito, Ecuador.

Ramírez (2017). Gestión del Sistema de Defensa Jurídica del Estado y las demandas de procesos contenciosos administrativos en la Unidad Ejecutoria 301-Eduación Bajo Mayo-San Martin, 2016. Universidad Cesar Vallejo, Tarapoto-Trujillo.

Citar como: Moreno Aguilar, J. D., \& Ruiz Paredes, G. (2021). Relación entre la vulneración del derecho de bonificación y su tratamiento en el proceso contencioso administrativo por preparación de clases de los docentes de la Unidad de Gestión Educativa Local - San Martín, 2018. Revista Científica Ratio lure, 1(1), 32-44. https://doi.org/10.51252/rcri.v1i1.126 
Izquierdo (2019). Cumplimiento de los principios del procedimiento administrativo y bonificación de preparación de clase y evaluación en la UGEL Moyobamba, 2019. Universidad César Vallejo.

Ley $\mathrm{N}^{\circ} 24029$ - Ley del Profesorado, modificada por la Ley $\mathrm{N}^{\circ} 25212$.

Decreto Supremo N 19-90-ED publicada en el Diario Oficial El Peruano el 29 de julio de 1990. Tribunal del Servicio Civil, informe legal 326-2012-SERVIR/GGOAJ

Tribunal Constitucional del Perú, Sentencia N 047-2011-PC.

Primera Sala de Derecho Constitucional y Social Transitoria en la Casación 8368-2016-San Martín (2018).

Corte Suprema de Justicia, Primera Sala de Derecho Constitucional y Social Transitoria (2018). Casación N 16286-2016- San Martín.

Corte Suprema de Justicia, Primera Sala de Derecho Constitucional y Social Transitoria (2018). Casación $N^{\circ} 7122-2016-$ San Martín.

Segunda Sala de Derecho Constitucional y Social Transitoria de la Corte Suprema de Justicia de la República (2015). Casación N 6871-2013-Lambayeque.

Salas, P. (2013). Los procesos administrativos contenciosos en el sistema de justicia peruano.

Citar como: Moreno Aguilar, J. D., \& Ruiz Paredes, G. (2021). Relación entre la vulneración del derecho de bonificación y su tratamiento en el proceso contencioso administrativo por preparación de clases de los docentes de la Unidad de Gestión Educativa Local - San Martín, 2018. Revista Científica Ratio lure, 1(1), 32-44. https://doi.org/10.51252/rcri.v1i1.126 


\section{Anexos}

\section{Conflicto de intereses}

No existe conflicto de interés.

\section{Contribuciones de los autores}

La contribución de cada autor se ha realizado de manera coordinada en el todo el proceso de elaboración. 